\title{
EFFECT OF SEX SEPARATION AT THE FINISHER PHASE ON THE COMPARATIVE GROWTH PERFORMANCE, CARCASS CHARACTERISTICS AND BREAST MUSCLE DEVELOPMENT BETWEEN MALE AND FEMALE BROILER CHICKENS
}

\author{
E.A.O. LASEINDE, and J.A. OLUYEMI \\ Department of Animal Production and Health, Federal University of Technology, Akure \\ Received 23 September 1993, Accepted 15 March, 1994
}

\begin{abstract}
Male and Female Anak strain of broilers were raised on deep litter to investigate the effect of separating the sexes at the finisher phase on growth performance, carcass characteristics and breast muscle development between the sexes. The day-old chicks were raised as mixed sexes for four weeks starter period. Thereafter, 108 of the starter birds were distributed into three sex groups - male, female and mixed, each group replicated thrice and uniformly fed finisher diet for six weeks. The birds were individually weighed weekly. Six birds representing each sex from each group were dissected at week 10 to compare performance in terms of external body parts, internal organs, fat depot, leg bones and breast muscles. There were no significant differences $(P>0.05)$ between male and female of either sex groups in weekly body weight gains, feed consumption, utilisation, weight of breast muscles, internal organs and fat deposit. Coefficient of variation was higher in male than female. Percentage male superiority was higher when the birds were raised as separated sexes than mixed. Male broilers raised as separate sex had significantly $(P<0.05)$ heavier neck and thigh than the female, while in the mixed sex group, the male was significantly $(P<0.05)$ higher than the female in back, breast, wing and tibia weights. Males in both sex groups recorded significantly $(P<0.05)$ heavier head, drumstick, shank and femur. The result from this study has shown that there is no statistically significant advantage for separating the broiler chickens into sexes as a
\end{abstract}

\footnotetext{
Present Address: *Department of Animal Science University of Ibadan, Ibadan.
}

management practice during the finisher phase.

Keywords: Sex separation, broiler finisher, performance

\section{INTRODUCTION}

Disparity in the growth rate of male and female broilers has been reported by many workers. Beginning from the embryonic stage, Burke and Shapp (1989) reported that the mean wet body weight of male embryo was significantly greater than that of the female at 11,13 and 18 days of incubation respectively. Male Chicks hatched from eggs heavier than 60 $\mathrm{g}$ significantly weighed more than the female from similar egg weight (Khan et al, 1975). Male broilers have also been reported to grow faster and heavier than female under various rearing conditions (Mandlekar and Desmukh, 1983; Sonaiya and Benyi, 1983; Fraga and Valdivis, 1985). Structurally, Yamani et al (1982) reported that males recorded higher values than females for some carcass measurements. Sonaiya et al (1990) reported that males had lower proportion of breast, breast meat and fat but higher proportion of leg, leg bones and total meat to fat ratio than females.

There had been few and conflicting reports on the practice of separating the broiler chickens into sexes while raising them. Most of the reports however were based on day-old sexing. Lang et al (1960) found no significant difference in body weight gain between the separated and mixed-sex-birds. While Gehel $t$ al (1974) reported that there was very little apparent benefit from rearing the sexes separately, North (1978) submitted that separate rearing of male and/female birds promoted earlier marketing of the males and greater uniformity in body weight of either sex at market 


\section{SEX SEPERATION AND BROILER PERFORMANCE}

age. Meijerhof (1988) also reported that birds separated into sexes had significantly lower feed intake than those managed as mixed-sexes.

Male and female broilers have different growth potentials which can be enhanced or otherwise by management. For example, although male broilers utilise feed more efficiently than the females (Musharaf and Latshaw, 1984; Mendez and Cury, 1986), the female broilers utilise dietary energy more efficiently than the males between weeks 5 and 8 of their growing period (Mendonca, 1983). From this report, there appears to be possible growth enhancing prospects in separating the sexes as a management practise during the finishing phase. This prospect has motivated this study. In addition, sexing birds at finisher phase is easier to practise by most farmers because the sexing is done by comb inspection rather than the more difficult vent inspection at day old.

This study is therefore aimed at separating the birds into sexes at the finisher phase and separately comparing the growth performance of male and female broilers when raised as separated and mixed sexes. The carcass characteristics as well as breast muscle development will also be compared between the sexes under each management group.

\section{MATERIALS AND METHODS}

\section{Management of experimental birds:}

Five hundred broiler chicks of the Anak suain were brooded together on deep litter floor for the four weeks starter period. Thereafter, 108 of them were selected, sexed, individually identified by leg-tagging and separated into three treatment groups - male, female and mixed. The first two groups constituted the separated treatments while the later represented the mixed-sex treatment. Each treatment was replicated thrice, 12 birds per replicate in a completely randomized design. The mixed group consisted of 6 male and 6 female birds per replicate. The birds in each replicate were raised in equidimensional pens with a floor space of $0.1 \mathrm{sq} \mathrm{m}$ per bird for $4-10$ weeks finisher phase.
The birds were uniformly fed ad libitum on starter diet for the first 4 weeks and finisher diet for the last 6 weeks, finisher phase (4-10 weeks). The nutrient compositions of the two diets are shown in Table 1. The birds were covered at day-old with intraoccular New Castle disease vaccine and at weeks 2 and 5 with the two doses of Gumboro vaccine. New Castle disease vaccine (Lasota) was administered through water at week 6. The birds were placed on coccidiostat at weeks 4 and 8

\section{Dissection procedure:}

At the end of the study in week 10, six birds from each of the separated-sex treatments and twelve ( 6 male and 6 femaie) from the mixed-sex treatment were randomly selected for dissection. The birds were dissected by standard methods as described by Laseinde (1991). The parts dissected were grouped into four viz - external body parts, internal organs and fat depot, leg bones and breast muscles.

The external body parts consisted of the head, neck, back breast, wings, thigh, drumsticks and shanks. Comparising the internal organs were the heart, lungs, liver, spleen, kidney, gizzard and pancreas. The leg bones were made up of the femur and tibia while the breast muscles dissected were the outer and inner muscles (Musculus pectoralis and $M$. supracoracoideus).

\section{Data collection and analysis}

The birds were weighed weekly to determine the body weight gains. Feed consumption and feed utilisation were determined weekly for the separated-sex treatments. Each dissected part was weighed on sensitive electronic Mettler balance. The body weight gains as well as the weight of each dissected part were analyzed for variance between the sexes under each treatment, using the $t-$ test. Feed intake and utilization data were similarly analyzed for birds under separated-sex treatment. The percentage. malc superiority was computed by using the following formula: 
$\mathrm{MS}=[(\mathrm{a}-\mathrm{b}) / \mathrm{b}] \times 100$

Where MS = Male superiority (\%)

$a=w t(g)$ for male; $b=w t(g)$ for female

The coefficient of variation was determined for body weight gain. Statistical analyses followed the procedures stated by Snedecor and Cochran (1976).

\section{RESULTS}

\section{Body weight gains:}

The average weekly body weight gains (BWG) of male and female birds under each sex group are presented in Table 2. There were no significant differences $(P>0.05)$ in weekly $B W G$ between male and female birds raised either as separated or mixed-sexes. There was however a trend in favour of males.

The average coefficient of variation $(\mathrm{CV})$ in BWG for the male and female birds showed that the males varied more in BWG than females, irrespective of whether or not the sexes were separated. The average CVs between the sexes in each group were generally close (31.82 and 29.63; 31.77 and $29.91 \%$ for the separated and mixed sexes respectively). The percentage male superiority in BWG was generally higlier when the sexes were separated than when mixed (Fig. 1).

\section{Feed intake and Feed Utilization:}

On weekly basis, there was no significant difference $(P>0.05)$ between the male and female birds in feed intake and utilization (Table 3), though the males consumed averagely more feed.

\section{External body parts and leg bones:}

Table 4 shows the average wet weights $(\mathrm{g})$ of the external body parts and leg bones between the male and female broilers under the two sex groups. Males were significantly superior $(P<0.05)$ to the female in the weight of head, drumsticks, shanks and femur under both sex groups. Male broilers raised as separate sex had significantly $(\mathrm{P}<0.05)$ heavier neck and thigh while within the mixed sexed group, male broilers recorded significantly $(P<0.05)$ higher values for back, breast, wings and tibia
Internal organs, fat depot and breast muscles:

There were no significant differences $(P>0.05)$ between the male and female broilers within each of the sex group in the mean wet weights of each of the internal organs, fat depot and two breast muscles (Table 5). Higher average values were however recorded for the males $\mathbf{A}$ most of them.

\section{DISCUSSION}

The insignificant differences in the weekly body weight gain (BWG) between the male and female broilers under the separated and mixed-sex groups indicate that sex has no significant effect on BWG. The higher average values for males is however supported by other workers (Mandlekar and Desmukh, 1983; Sonaiya and Benyi, 1983; Fraga and Valdivis, 1985). The result further shows that sex-separation has no significant effect on BWG generally which is corroborative of the findings of Lang et al (1960). Comparing the average values between the separated and mixed sexes however, the result suggests that though sex scparation enhances the average growth of both male and female, it is of greater value to the male than the female.

Though there were no significant differences in the feed intake and utilization between the sexes, the higher intake values for male agree with the reports of Marks (1986 and 1987). Similarly, the apparent better feed utilization of the male is in agreement with the reports of Sonaiya and Benyi (1983), Musharaf and Latshaw (1984), Reece et al (1984) and Mendes and Cury (1986).

In both scx groups, the male was significantly superior in the weights of head, drumstick, shank and femur. The greater prominence of the comb and wattle in the male would be responsible for heavier male head. The greater ambulatory activity of the male within the deep litter pen could explain the higher values for drumsticks, shanks and femur in males. Widdowson (1980) reported that growth of body part is enhanced by activity and Fischer (1975) 
indicated that male birds are behaviourally more active than the females in a mixed-sex environment. This is also probably why the male was significantly superior to the female in wing weight under the mixed-sex group.

Growth of internal organs besides the reproductive organs do not seem to be significantly dependent on the sex of the birds nor the sex-grouping management system used in rearing them. This explains why there were no significant differences between the male and female in the weights of the internal organs. It is however remarkable to note the higher values recorded for the males under both groups for some of the organs. Considering the heart and the lungs for example, the higher male cardiac output (Sturkic, 1976) which normally involves oxygenation could be responsible for the heavier heart and lung of the male broilers. The higher feed intake of the male is correspondingly responsible for the heavicr gizzard weight. The females tend to have more lymphoid tissues as manifested in the heavicr spleen.

Thz female broilers recorded heavier abdominal fat deposit under the separated sex group. Unlike under the mixed-sex condition, the females apparently had no competition with the males for feed, hence fed more frecly under the separated-sex environment. This could have been responsible for their depositing more fat under this later condition than the males. Mendes and cury (19\$6) and Sonaiya at at (16)(t) reported that female broilers generally deposit more fat in their carcasses than males. (iencrally, the mate broikers developed more breast muscles than the fomale, though not statistic. Ily significant, a trend which follows the higher bidy weight gains recorded for the males.

Thewgh differences between male and female was not too pronounced under each of the separated and mixed-sex grotess in terms of external hody parts and incernal organs, the performance of the hirds in terms of body weight gains under the separated-sex group gives an indication that there could be some benclit in sejaratiog the sexes at ibe linisher phase. Such benefit, however, has not been shown to be statistically significant.

\section{REFERENCES}

BURKE, W.H. and P.J. SHARP (1989). Sex differences in body weight of chicken embryos. Poultry Sci. 68:805-810

FISCHER, G.J. (1975). The behaviour of chicken. In: Bailliere Tindal. pp. 454-487

FRAGA, L.M. and M. VALDIVIS (1985). The utilisation of crude oil sediment in the finishing rations for broilers. Cuban J. of Agric. sci. 19:197-202

GEHLE, M.H., T.S. POWELL and L.G. ARENDS (1974). Effects of different feeding regimes on performance of broiler chickens reared sexes separately or combined. Poultry Sci. 53: 1543-1548

KHAN, A.G., M.V. POULOUSE and S. CHAKRABORII (1975). Sexual dimorphism in the weight of chicks British Poultry Sci. 16: 637-639

LANG, B.J., W.M. COLLINS, D.H. PALMAR and W.C. SKO(iLUND (1960). Relationship of sex separation to individual variation in body weight and to experimental crror. Poultry sci. 39: $1578-1579$

LASEINDE, E.A.(). (1991). The structural basis and the influcnee of genotype and management on sexual dimorphism in the growth of the domestic fowl (Gallus domesticus) Ph.D. thesis, University of lbadan, Nigeria, pp. 55-59

MANDLEKAR, S.M. and S.N. DESMUKH (1983).Relationship hetween 8 week body weight and eviscerated weight in broiler chickens. Avian Res. 67 (3):96-100

MARKS, H.L. (1966). The role of water intake (n) sexual dimorphism for early growth of broilers. Pouliry Sci. 6.5: 433-435

MARKS, H.L. (1487). Sexual dimorphism in brotiers following periods of equal water and feed intake. Poultry Sci. 63: 1617-1625

MEIIERHOF, R. (19K8). Scparate sex feeding at the Dutch regional experimental poultry farms. Proc. of the 4th International Poultry Brecders Conf. pp. 40-40, 
MENDES, A.A. and P.R. CURY (1986). Effects of dictary energy levels and sex on broiler performances and carcass traits. 7 th European Poultry Conf. Paris, 1986. Vol.1 Genetics Nutrition, Posters Ed. by $\mathbf{M}$. Larbier pp. 543-547

MENDONCA JR., C.X. DE (1983). Effect of the amount of energy in the diet on performance and carcass yiclds of broiler chickens. Revista de faccildade de Medicina Veterinaria e Zoo tecnia da Uriversidade de San Paulo (1983) 20 (2) 161 175. In: Poultry Absi. (1986) 12 (4) 102:862

MUSHARAF, N.A. and J.D. LATSHAW (1984). Different protein levels in broiler finisher diets and their effect in protein and energy utilization. J. of Egyptian Vet. Med. Assoc. 44:10\%-119

NORTH, M.O. (1978). (ommercial chicken production manual. 2nd Ed. AVI. Publ. Co. Inc. Westport, Connecticut.

REECE, F.N., B.D. LOTT and U.W. DEATON (1944). The effece of leed form, protein profile, energy levels and gender on broiler performance in warm $20.7^{\prime \prime} \mathrm{C}$ ) cnvirumment. Poultry Sci. (3:190)(-1911.
SNEDECOR. G.W. and W.G. COCHRAN (1976). Statistical methods. 6th Ed. Iowa state University Press, Ames, Iowa.

SONAIYA, E.B. and K. BENYI (1983). Abdominal fat in 12 to 16 - week-old broiler birds as influenced by age, sex and strain. Poultry Sci. 62:1773-1799

SONAIYA, E.B., M. RISTIC and F.W. KLEIN (1990). Effect of environmental temperature, dictary energy, age and sex on broiler carcass portions and palatability. British Poultry Sci. 31:121-128

STURKIE, P.D. (1976). Avian physiology. 3rd Ed. Springer Verlag. New York. p! 91-92

WIDDOWS()N, E.M. (1980). Definitions of growth. In: Growth in animals (1980). Butterworths, Lond : $\mathrm{pp} .1$

YAMANI, K.A.O., M.E. NOWAR, I.F.M. MARAI, A.M. IRKY and A.M.S. EID (1982). Studies on body measurements and dressing weights of broiler chicks. Egyptians J. of Anim. Prod. 22: 19-26.

Table 1 NUTRIENT COMPOSITION OF THE BROILER STARTER AND FINISHER DIETS

\begin{tabular}{lll} 
NUTRIENT & STARTER & FINISIER \\
\hline Crude Protein $(\%)$ & 21.16 & 20.27 \\
Crude Fibre $(\%)$ & 3.52 & 4.34 \\
Fal $(\%)$ & 4.76 & 4.8 .3 \\
Met. Energy $(\mathrm{Kcal} / \mathrm{Kg})$ & $2.70)$ & $2,8.50$ \\
Calcium $(\%)$ & $1.6 \%$ & $1.0 \mathrm{~K}$ \\
Phosphorus\% & 11.62 & 0.46
\end{tabular}



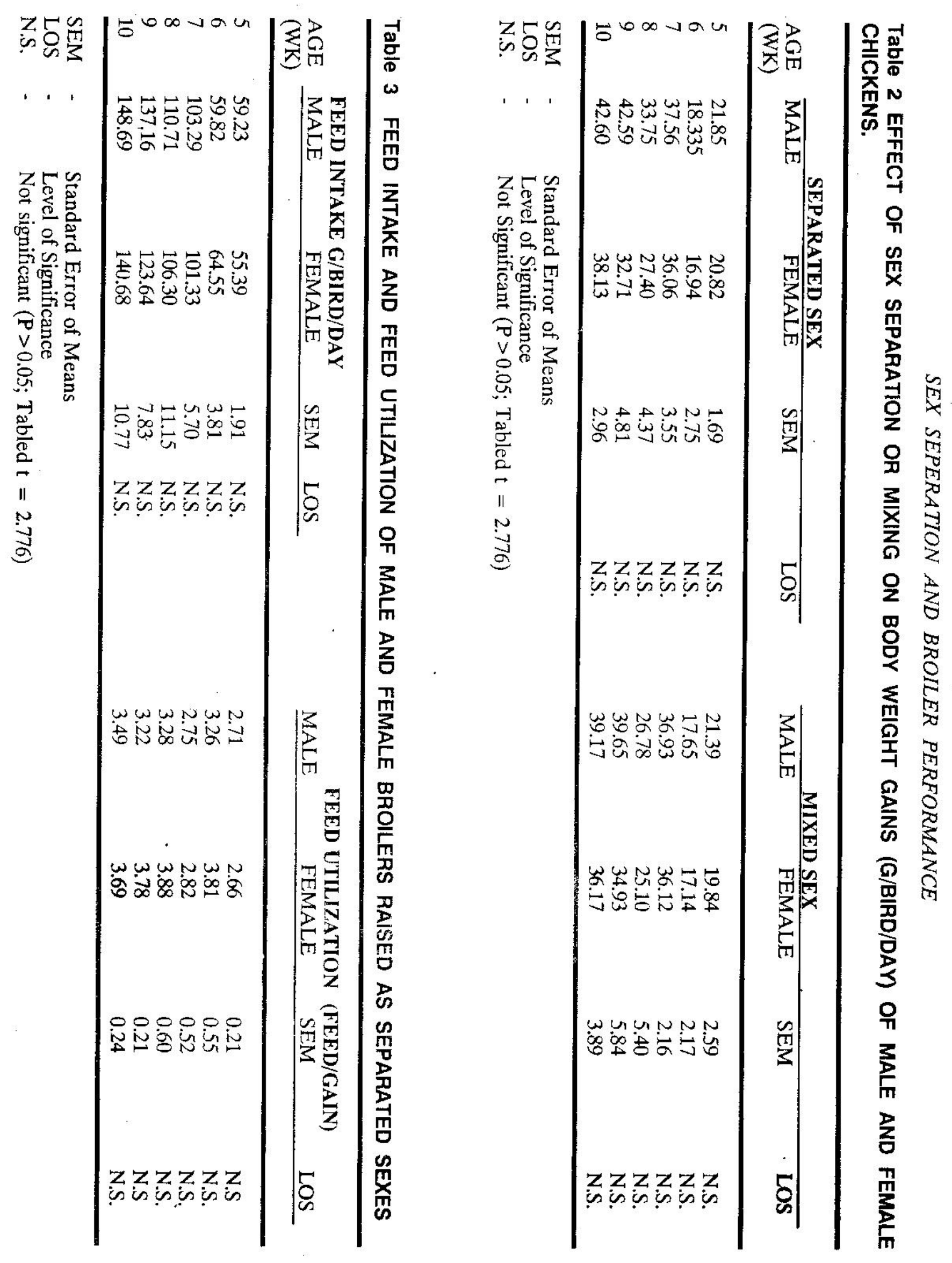


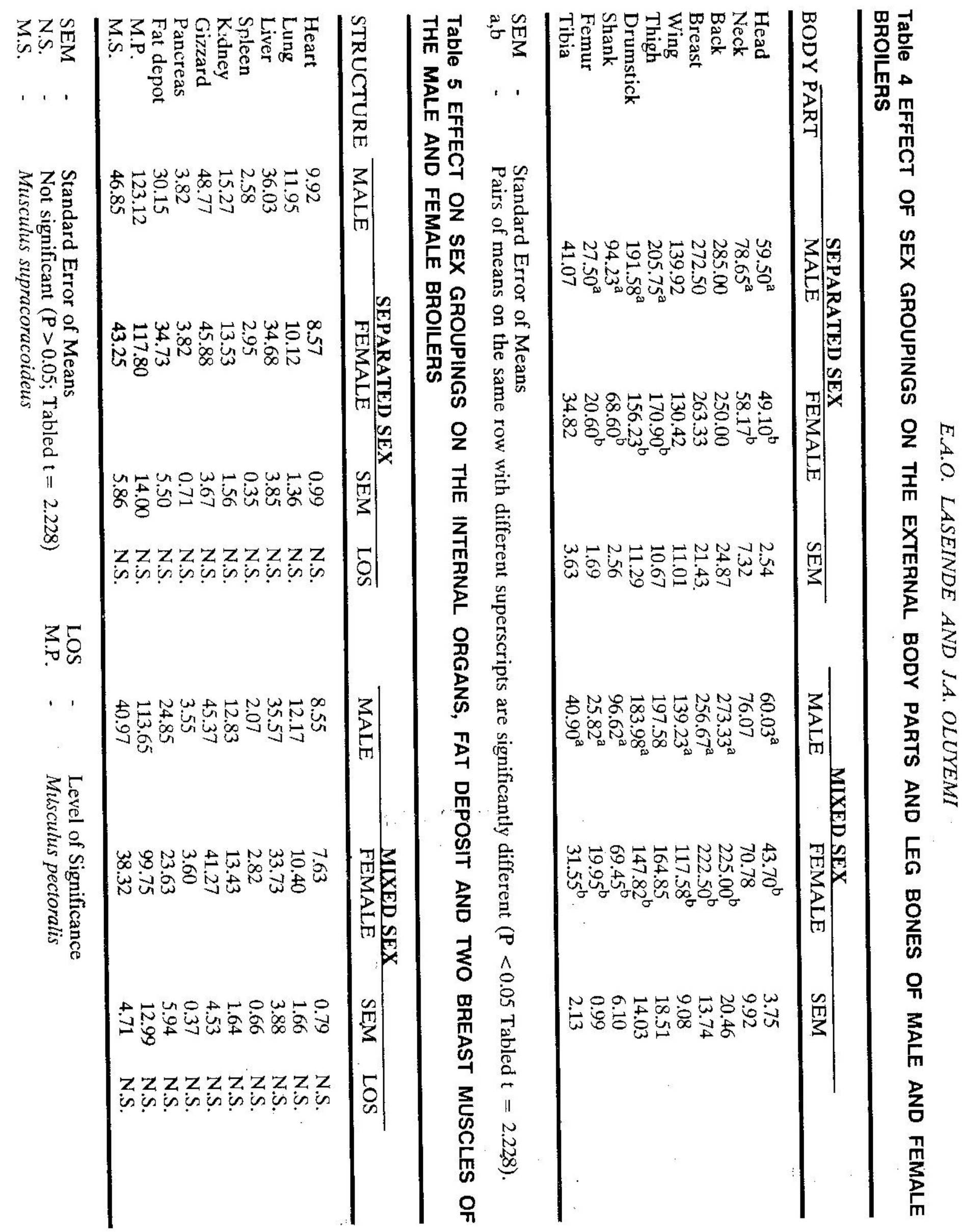




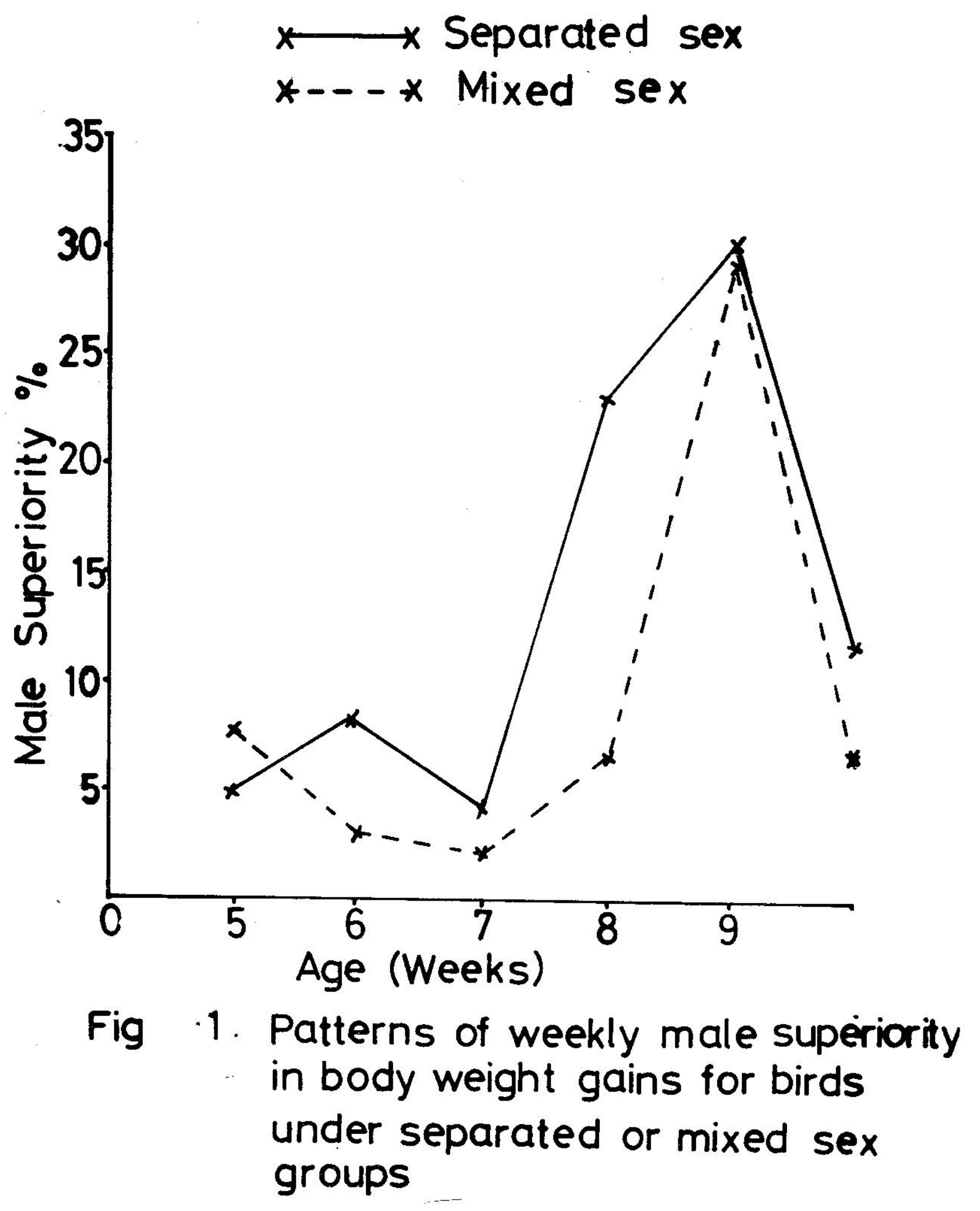

